\title{
Aspectos anatómicos de la semilla de papaya (Carica papaya L.)
}

\author{
Anatomical aspects of papaya \\ (Carica papaya L.) seed
}
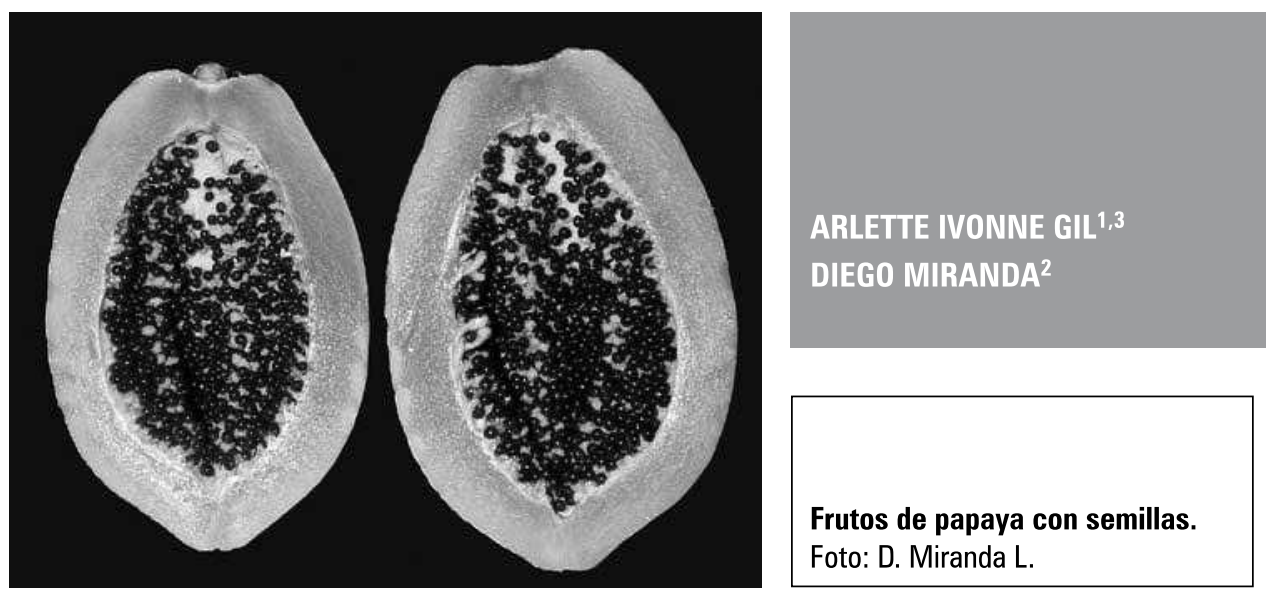

\section{RESUMEN}

Debido a la falta de estudios anatómicos en semillas de especies de interés económico, y el poco conocimiento de este tópico para los ingenieros agrónomos, se procedió a la realización de una investigación base para su entendimiento y posterior ampliación en futuros estudios. Con este fin se analizaron diversos aspectos anatómicos de la semilla de papaya, para lo cual se tomaron frutos inmaduros de 60 días y frutos maduros entre 120 y 150 días, entre madurez fisiológica y comercial, en una plantación sembrada con el híbrido Tainung-1. Las semillas extraídas de los frutos mencionados fueron llevadas al laboratorio y adecuadas mediante la técnica de parafina, para posteriormente realizar los cortes en micrótomo de rotación con el propósito de describir anatómicamente los tejidos y estructuras que las componen, bajo microscopía óptica. La semilla de papaya está compuesta por la cubierta seminal, el endospermo y el embrión. Por tratarse de una semilla bitegumentada, se observaron la testa y el tegmen con sus correspondientes componentes. El endospermo está compuesto principalmente de lípidos y proteínas agrupados en granos de aleurona. Los cotiledones están compuestos además de la epidermis, por cuatro capas celulares internas y en la zona radicular se pudo apreciar el esbozo de raíces secundarias. Este estudio tuvo como objetivo generar conocimiento acerca de la anatomía de la semilla de papaya, para el entendimiento de aspectos básicos de la fisiología de semillas como vigor, viabilidad y latencia en esta especie, previo para futuras investigaciones.

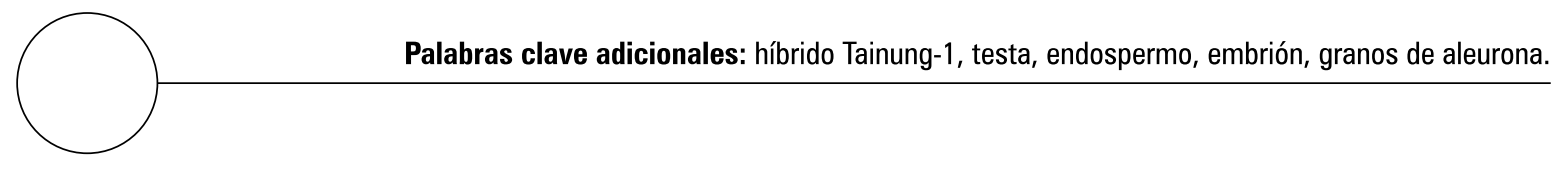

Facultad de Ciencias Agropecuarias, Universidad de Cundinamarca, Fusagasugá (Colombia).

Departamento de Agronomía, Facultad de Agronomía, Universidad Nacional de Colombia, Bogotá (Colombia).

Autor para correspondencia. arlettegil@hotmail.com 


\section{ABSTRACT}

Due to the lack of the anatomical studies in seeds of the species of economical interest and a few knowledge of this matter by the agronomists, the investigation as a base for understanding of this problem and further development in future studies was done. With this purpose, several anatomical aspects of papaya seed were analyzed from immature fruits of 60 days age and mature fruits of 120 and 150 days between physiological and commercial maturity were taken from Tainung-1 hybrid plantation. The seeds extracted from fruits were transported to the laboratory and adequated with paraffin technique to make the microtome sections in order to describe anatomically the tissues and structures under optical microscopy. Papaya seed is composed of the seed coat, endosperm, and embryo. As a bitegumental seed, the testa and tegmen were observed with their own parts. The endosperm is composed mainly of lipids and proteins grouped in aleurone grains. The cotyledons are composed by the epidermis and four-layer inner cells and, in the radicle zone, initiation of the secondary roots was observed. The objective of this study was to generate knowledge about the anatomy of papaya seed for understanding the basic aspects of seed physiology, such as vigour, viability, and dormancy in this species, prior to future researches.

Additional key words: Tainung-1 hybrid, testa, endosperm, embryo, aleurone grains.

La papaya (Carica papaya L.) es considerada de origen Americano, específicamente de Centroamérica, entre México y Costa Rica (León, 1987). La identificación de las distintas características morfológicas y fisiológicas es un paso inicial importante en el estudio del desarrollo de las semillas en las diversas especies (Ren y Bewley, 1998). El megasporangio (óvulo) es la estructura a partir de la cual se forman las semillas. En las angiospermas está formado por uno o dos tegumentos, ocasionalmente por tres, y muy raramente por cuatro. En la semilla madura, los tegumentos que rodean al óvulo se transforman en la cubierta seminal (Niembro, 1988; Reiser y Fischer, 1993).

Las semillas de las angiospermas pueden ser divididas en tres partes, de origen genéticamente diferente: el embrión, el endospermo y la cubierta seminal. El cigoto, a partir del cual se desarrolla el embrión, combina los genotipos del haploide masculino y el gameto femenino. Después de la fertilización, durante el desarrollo del embrión y la subsiguiente maduración de la semilla, los integumentos experimentan cambios morfológicos y se convertirán en la testa, la cual posee el genotipo materno (Fosket, 1994; León-Kloosterziel et al., 1994). Debido a que el embrión está encerrado por el endospermo, el cual a su vez está dentro del integumento del óvulo, estas tres estructuras deben coordinar su desarrollo para producir una semilla madura de tamaño adecuado (García et al., 2003).

Cuando la semilla proviene de un primordio seminal con un solo tegumento, es unitegumentada y su cubierta seminal se denomina testa. Igualmente si el primordio posee dos tegumentos, los tejidos derivados del tegumento externo constituyen la testa y los derivados del tegumento interno conforman el tegmen, cuando la semilla es bitegumentada (Becerra y Chaparro, 1999). 
El endospermo es un tejido que se origina a partir de la fusión de uno de los núcleos espermáticos del grano de polen con dos núcleos polares del saco embrionario, dando como resultado un tejido triploide (Becerra y Chaparro, 1999). El endospermo acumula la mayor parte de las reservas nutritivas en la mayoría de los casos cuando los cotiledones no lo hacen (Esau, 1985; Besnier, 1988). Algunas semillas pueden presentar un endospermo muy delgado, limitado a una o varias células de grosor, o bien pueden estar provistas de uno masivo, parenquimatoso (Fahn, 1985). El endospermo es único en diversos aspectos de su desarrollo, biología celular y bioquímica. Su aparente simplicidad reflejada en la presencia de unos cuantos tipos de células diferenciadas, ha permitido estudios detallados en histodiferenciación y biosíntesis de ciertos metabolitos almacenados (Lopes y Larkins, 1993).

El encerramiento del embrión y del endospermo en integumentos de origen estrictamente maternos, ha llevado a interacciones entre los tejidos de diferentes contribuciones parentales en la protección del embrión y del endospermo, y en el control de la protrusión radicular de las semillas. Tales interacciones influencian la germinación, latencia, calidad de la semilla, en particular vigor y longevidad (Debeaujon et al., 2000).

El embrión de las angiospermas consta de un breve eje que lleva uno o dos cotiledones u hojas embrionales. El punto de fijación de los cotiledones al eje, designado como nudo cotiledonar, divide al eje en dos regiones: basal o hipocotilo que termina en una raíz embrionaria o radícula, y la región superior o epicotilo que puede presentar una yema denominada plúmula (Becerra y Chaparro, 1999).

El objetivo de esta investigación consistió en generar un conocimiento básico acerca de la estructura de la semilla de papaya, con el fin de servir como base para futuros estudios en el área de anatomía y fisiología vegetal.

\section{MATERIALES Y MÉTODOS}

En la finca Santa Helena propiedad del grupo Grajales S.A., se realizó el muestreo de frutos de papaya del híbrido Tainung-1 cuyo origen es taiwanés, con el fin de extraer sus semillas. La plantación se encuentra ubicada en el municipio de Roldanillo (Valle del Cauca, Colombia), a una altura de $935 \mathrm{msnm}$, temperatura de $24,2^{\circ} \mathrm{C}$, precipitación anual de $1.015 \mathrm{~mm}$ y humedad relativa de $71,1 \%$.

Se tomaron frutos inmaduros, de $60 \mathrm{~d}$ de edad, que contenían rudimentos de semillas (primordios seminales) y frutos maduros (madurez fisiológica y comercial) entre 120 y $150 \mathrm{~d}$. Las semillas (figura 1) se extrajeron de los frutos y fueron acondicionadas según la metodología de Johansen (1940), en la cual el material vegetal (semilla) fue incluido en bloques de parafina para posteriormente proceder a los cortes en micrótomo de rotación, con el fin de estudiar su anatomía bajo microscopio óptico. Para el teñido del material se utilizó Fast Green y safranina.

\section{RESULTADOS Y DISCUSIÓN}

\section{Primordios seminales}

En el corte transversal medio realizado a un fruto inmaduro de $60 \mathrm{~d}$, se observó que las semillas en formación (primordios seminales) se encontraban adheridas a las paredes internas del fruto por medio del funículo, lo que se conoce como placentación parietal (figura 2). Esta característica ayuda a clasificar a la papaya dentro del orden de las parietales, lo que ratifica lo afirmado por Font Quer (1965). Al interior del funículo se observaron de seis a siete capas de células muy alargadas, correspondientes al haz conductor, con unas pocas diferenciadas en xilema, de engrosamientos anulares. En este estado, las células del rudimento presentaban la apariencia de células embrionarias, con paredes delgadas y nú- 
cleos prominentes, como evidencia de la división activa a la que se encontraban sometidas.

Stadler et al. (2005) mostraron en semillas de Arabidopsis thaliana que el integumento externo es una extensión simplástica del floema del funículo, sugiriendo que los nutrientes al final de este pueden ser descargados a través de este tejido. El transporte de sacarosa en el funículo indica que esta es una vía común para la descarga de nutrientes a las semillas en desarrollo (Skinner et al., 2004). La asimilación de carbono es suplida hacia el embrión en desarrollo. Los haces vasculares están conectados al óvulo a través del funículo al final del tejido nucelar. Los tejidos vasculares no se extienden más allá del funículo dentro del óvulo (Imlau et al., 1999).

La epidermis que recubría el funículo y la parte externa de la semilla correspondía a la continuación de la epidermis interna del fruto, constituida por células de forma rectangular, un poco más altas que anchas, con la pared externa algo arqueada, a modo de las células epidermales típicas. Al analizar la parte interna del rudimento, se observaron células un poco más anchas, muy juntas, que se unían sin dejar espacios entre sí. La cubierta seminal, que es la estructura de protección de la semilla contra los agentes externos, se deriva de estos tegumentos dispuestos de forma concéntrica (figura 3). Las seis capas subyacentes a la epidermis, constituyentes del tegumento externo, midieron $7 \mu \mathrm{m}$ de espesor, presentando forma aplanada y disposición regular. Hacia la parte interna se observaron unas 10 capas celulares, correspondientes al tegumento interno, con paredes angulares de formas y tamaños diversos, cuyo espesor fue de $7,5 \mu \mathrm{m}$.

Los óvulos son el sitio de los procesos esenciales para la reproducción sexual de las plantas, incluidas la formación del megagametofito, fertilización, embriogénesis y, finalmente, la formación de la semilla. En Arabidopsis, los óvulos se inician en los primordios con una forma alargada a partir de la placenta de la superficie interna de los carpelos (Skinner et al., 2004). Los integumentos interno y externo surgen de cada primordio del óvulo, con su región de origen definiendo la chalaza, la cual separa la nucela apical del funículo. Los dos integumentos crecen para cubrir y encapsular la nucela, teniendo una pequeña abertura, el micrópilo. El funículo provee la conducción de nutrientes al óvulo en desarrollo y al embrión, y determina parcialmente la posición del micrópilo. Los integumentos son requeridos para encerrar el saco embrionario, contribuyendo al posicionamiento del óvulo para posteriormente formar la cubierta seminal. La nucela provee el inicio celular para la diferenciación del megasporocito, el cual, por procesos de mitosis y meiosis, produce un megagametofito llamado saco embrionario (Webb y Gunning, 1990).

\section{Semilla madura}

Al observar una vista parcial del corte transmediano de estas semillas, se diferenciaron claramente tres zonas de tejidos: la cubierta seminal, el endospermo y el embrión (figura 4).

La elongación celular en la cubierta seminal está dirigida por el crecimiento del endospermo y es el mayor responsable en el control del tamaño de la semilla. La proliferación celular ocurre en la cubierta seminal después de la fertilización y también puede cumplir un papel importante en el tamaño de la semilla (Garcia et al., 2005; Ingouff et al., 2006; Schruff et al., 2006). Sin embargo, es desconocido si la proliferación celular es regulada en la cubierta seminal en respuesta a la fertilización. Además las interacciones involucran la proliferación celular y la elongación en la cubierta seminal, y la evidencia ha sido obtenida por la interacción de la diferenciación entre el endospermo y la cubierta seminal en cebada (Hordeum vulgare L.) y maíz (Zea mays L.) (Chaudhury y Berger, 2001).

La cubierta seminal estuvo constituida por cuatro capas de coloración diferencial, denominadas exotesta, mesotesta, endotesta y tegmen (figura 5). 
La zona más externa consistió en varias capas de tejido de paredes delgadas y transparentes, con forma rectangular y dispuestas en empalizada, elongadas radialmente y organizadas sin dejar espacios entre sí, recordando la organización típica de las capas epidermales. Estas capas constituyeron la sarcotesta, que corresponde a la exotesta jugosa que recubre a las semillas de papaya. Hacia el interior se encontraron hasta 15 capas de células escleróticas cuboides o elongadas tangencialmente, que constituyeron la parte dura y oscura de la cubierta seminal. Estas células poseían lúmenes grandes que al unirse dejaban pequeños espacios entre sí, dando la apariencia de una malla con unidades de forma estrellada. Al final de las aristas formadas por las paredes, en la conjunción de tres células, se formaba un espacio en forma de triángulo. Esta capa formaba la parte rugosa de la semilla, que es posible observar una vez se ha removido la exotesta. El número de capas celulares que la constituía determinaba los valles y los picos en las rugosidades, y conformaban la mesotesta externa de la semilla. Inmediatamente por debajo de esta capa, se encontró otra de unas 25 filas de células también esclerenquimáticas, de entre 0,5 a $1 \mu \mathrm{m}$ de alto por $1 \mu \mathrm{m}$ de ancho, con un grosor de $16 \mu \mathrm{m}$. Las células fueron de forma ovoide, más anchas que altas y se unían entre sí sin dejar espacios. En conjunto esta capa se denomina mesotesta interna (figura 6).

La capa subyacente o endotesta estuvo constituida por una fila de células esclerenquimáticas redondeadas, con la pared tangencial interna ligeramente engrosada y lignificada, con una altura de $3 \mu \mathrm{m}$ y ancho de $1,5 \mu \mathrm{m}$. Debajo de esta capa fue posible observar el exotegmen y el mesotegmen, que estaban formados por células entrecruzadas. La capa más interna de la cubierta seminal, correspondiente al endotegmen, estuvo constituida por una fila de células rectangulares, de 0,7 $\mu \mathrm{m}$ de alto por $2 \mu \mathrm{m}$ de ancho, cuyo contenido celular estaba constituido por taninos. Seguidamente se observó la cutícula nucelar, en contacto con el endospermo de la semilla (figura 7).
Durante el desarrollo de la semilla, cada integumento se encamina hacia un dramático proceso de diferenciación para formar la cubierta seminal madura: algunos de los tejidos que son generados en los estados tempranos e intermedios del desarrollo de la semilla desaparecen en los estados tardíos en semillas de Brassicaceae (Beeckman et al., 2000; Western et al., 2000; Windsor et al., 2000). Durante el proceso de diferenciación, el tegumento interno llega a comprimirse e impregnarse con pigmentos que le imparten la característica de color marrón, sin embargo, los mecanismos moleculares bioquímicos base de este proceso no son del todo entendibles (Nakaune et al., 2005).

El endospermo se observó de consistencia carnosa y suave, externo al embrión. Cada lado de este tuvo cerca de 16 capas de células parenquimáticas. Las células de las seis más externas fueron de forma rectangular, mientras que las capas internas estuvieron constituidas por células isodiamétricas de forma poliédrica. Los lípidos y las proteínas son las sustancias de reserva almacenadas en el endospermo de la semilla de papaya. Los lípidos se pudieron observar como oleosomas, mientras que las proteínas se encontraron almacenadas en pequeñas estructuras llamadas cuerpos proteínicos o granos de aleurona, las cuales presentan gran similitud en tamaño y forma con los granos de almidón (figura 8). Las paredes celulares en este tejido de reserva son delgadas, de acuerdo a lo reportado por Niembro (1988).

El endospermo es un tejido único. Debido a su rol central en la nutrición y protección del embrión, el desarrollo del endospermo está sujeto a los procesos adaptativos, los cuales conllevan a la evolución del origen parental dependiente de la regulación genética (Baroux et al., 2007). El endospermo es un tejido efímero restringido al periodo de producción de semilla y germinación. Es mayormente consumido tanto por el embrión en desarrollo o después de la germinación de la semilla. La inusual constitución genética del endospermo puede ser vista desde la contribución 
parental como una fuente de heterocigosis proveyendo vigor poliploide -un estado genético beneficioso para la alta tasa de proliferación y metabolismo del endospermo (Lopes y Larkins, 1993)-. Además de su función como tejido de reserva, el endospermo ha demostrado ejercer control sobre la germinación, al secretar enzimas que aflojan la pared celular debilitando la resistencia mecánica para facilitar la protrusión radicular (Penfield et al., 2006).

Haig y Westoby (1989) proponen que la triplodía y el origen biparental del endospermo puede ser el resultado de conflictos genéticos parentales sobre la localización de la fuente a partir del esporofito materno a su progenie. La doble fertilización pudo primero evolucionar para transmitir los intereses del padre en promocionar su tasa de crecimiento en la progenie, mientras que el doble genoma materno puede ser visto como una respuesta evolutiva para reforzar los intereses de la madre en la repartición equitativa de recursos entre hermanos.

Las semillas acumulan lípidos con el fin de suplir los requerimientos energéticos para el crecimiento de la plántula después de la germinación. Tales lípidos son generalmente acumulados como triacilgliceroles (TAG) en compartimientos esféricos conocidos como esferosomas, oleosomas o más comúnmente, cuerpos lipídicos. Esos organelos emergen del retículo endoplasmático, el cual es responsable de la síntesis de TAG (Siloto et al., 2006). La glicólisis es una vía ubicua esencial para la producción de aceite en semillas en desarrollo de Arabidopsis thaliana y cultivos oleaginosos. Una importante función metabólica del desarrollo de la semilla de esta especie, es la deposición de sustancias de reserva -aceite en la forma de triacilgliceroles, pero también proteínas y oligo y polisacáridos (Andre et al., 2007)-. En semillas no endospérmicas, como Brassica spp, los cuerpos lipídicos se encuentran en los cotiledones y el eje embrionario. En Ricinus communis y otras semillas endospérmicas, los cuerpos lipídicos pueden ser encontrados en el endospermo (Anil et al., 2003).

El embrión estuvo limitado por la protodermis, la cual estaba formada por células entre 0,7 a 1,2 $\mu \mathrm{m}$ de alto por 3,0 a 3,5 $\mu \mathrm{m}$ de ancho. Las células protodermales fueron homogéneas y se unían entre sí, sin dejar espacios. Por debajo de la protodermis, en el plano medio del embrión, se encontraron de ocho a nueve capas de células, que constituían el parénquima fundamental cortical. Las células se observaron de forma cuadrangular (de 0,8 a 1,2 $\mu \mathrm{m}$ de alto por 1,2 a $1,4 \mu \mathrm{m}$ de ancho), agrupadas sin dejar espacios intercelulares y formando columnas. Al interior se encontraron de siete a ocho capas de procambium a cada lado del embrión. Las células midieron de 2,0 a 2,8 $\mu \mathrm{m}$ de alto por 0,6 a 1,0 $\mu \mathrm{m}$ de ancho. La parte interna estuvo constituida por cinco capas de células, que midieron entre 1,7 y $2,0 \mu \mathrm{m}$ de alto por 2,0 a 2,4 $\mu \mathrm{m}$ de ancho, las cuales se denominan parénquima fundamental medular (figura 9).

Durante la embriogénesis, se establece un plan para el establecimiento del cuerpo de la planta que consiste en el meristemo aéreo, cotiledones, hipocotilo, raíz y meristemo radicular a lo largo del eje apical-basal y un arreglo concéntrico de la epidermis, el tejido subepidermal y el cilindro central vascular a lo largo del eje radial -para establecer esta organización, las células del embrión necesitan especializarse y deben diferenciarse (Laux et al., 2004)-.

En el ápice del embrión se encontró la túnica, que es el promeristemo que origina primero a la protodermis y posteriormente a la epidermis de la planta, de acuerdo con Barton y Poethig (1993). Estas células se dividieron de forma anticlinal y en las semillas de papaya estuvo constituida por una sola capa. Debajo de la túnica se encontró el cuerpo o corpus, que es el promeristemo del cual se originan los demás órganos de la planta. Las células que lo constituyeron fueron en su mayo- 
ría de forma redondeada, con cuatro a seis capas de células (figura 10).

El crecimiento del ápice del embrión puede ser visto en términos de tres parámetros celulares. El primero se manifiesta como una polaridad regional que puede distinguirse por los planos de división celular en diferentes capas en el meristemo apical. En las capas superficiales que constituyen la túnica, las divisiones celulares son predominantemente anticlinales (nuevas paredes celulares se forman perpendicularmente a la superficie del eje). En contraste, las células más internas constituyen el cuerpo o corpus y experimentan divisiones en una variedad de planos (Szymkowiak y Sussex, 1996).

Los cotiledones fueron ovados y de posición recta, planos y delgados. Además de la epidermis abaxial y adaxial, poseían cuatro capas celulares internas, cuyo grosor fue de $14 \mu \mathrm{m}$, en donde se observó cierta organización de las capas parenquimáticas internas: la primera de ellas en empalizada, la subyacente estuvo constituida por células ovoides de gran tamaño alternando con grupos de tres células de forma similar pero de menor tamaño, y las dos últimas se constituían de células más o menos cuadrangulares, por debajo de las cuales se encontró la epidermis abaxial (figura 11).

En dicotiledóneas, los cotiledones son órganos laterales y el meristemo apical está en una posición central, mientras que en monocotiledóneas el cotiledón es terminal y el meristemo apical está en una posición lateral. Los cotiledones se forman durante la embriogénesis y también están definidos como epígeos si emergen por encima del suelo, se expanden después de la germinación y llegan a ser fotosintéticos, o hipógeos, si ellos permanecen por debajo del suelo, no se expanden y permanecen no fotosintéticos. Los cotiledones pueden ser estructuras efímeras, persistiendo solamente por unos pocos días después de la emergencia, o pueden ser retenidos por la planta a través de su ciclo de vida (Chandler, 2008).
La polaridad de los cotiledones y las hojas es establecida para ambos órganos con respecto al meristemo apical, siendo la superficie adaxial la más cercana al eje de la planta o al meristemo apical, y derivándose a partir del dominio central apical del embrión, y el lado abaxial, opuesto y generado por el dominio periférico del embrión. Las superficies adaxiales y abaxiales de los cotiledones son morfológicamente distintas con respecto al tamaño celular y densidad estomática: la epidermis adaxial posee células de tamaño uniforme y tiene una superficie aplanada con una baja densidad estomática, mientras que la superficie abaxial tiene entremezcladas células grandes y pequeñas, una superficie áspera y alta densidad estomática (Siegfried et al., 1999).

En la zona radicular fue posible observar el esbozo de raíces secundarias de forma semicircular (figura 12). Las raíces laterales se originan por divisiones en el periciclo, dando como resultado una masa pequeña de células, que crecen atravesando la endodermis, el córtex, la epidermis, para brotar como una raíz joven. La epidermis (rizodermis) estuvo conformada por un estrato de células estrechamente unidas. En el córtex, las células fueron de forma alargada, de paredes delgadas, como las células parenquimáticas. En la endodermis, las células se observaron muy unidas, sin dejar espacios. El periciclo constó de una sola capa de células de paredes delgadas.

En $A$. thaliana, las raíces laterales se forman a partir de las células del periciclo adyacentes a los polos del xilema. El desarrollo de las raíces laterales está regulado antagónicamente por auxinas $y$ citoquininas. Mientras que es ampliamente conocido cómo las auxinas promueven el desarrollo de raíces laterales, el mecanismo represor de las citoquininas aún no es claro. Elevados niveles de citoquininas desorganizan la iniciación de raíces laterales y el patrón de división regular que caracteriza el desarrollo lateral de raíces en Arabidopsis (Laplaze et al., 2007). 


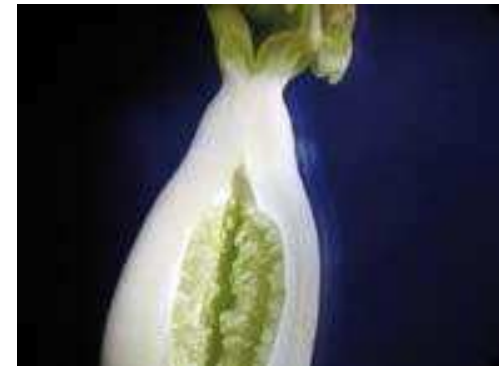

A

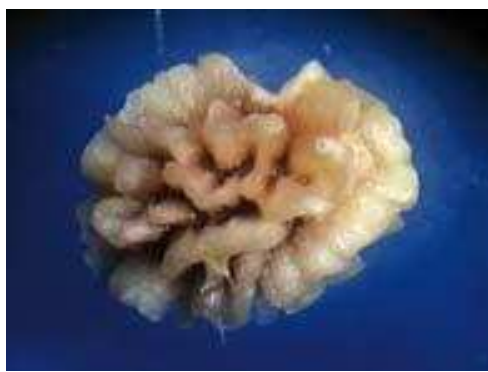

B

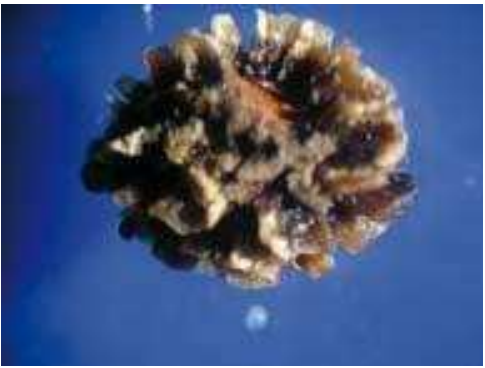

C

Figura 1. Tipo de semillas utilizadas para los cortes en micrótomo. A, primordios seminales de 60 días; B, semilla de fruto de 120 días; C, 150 días.

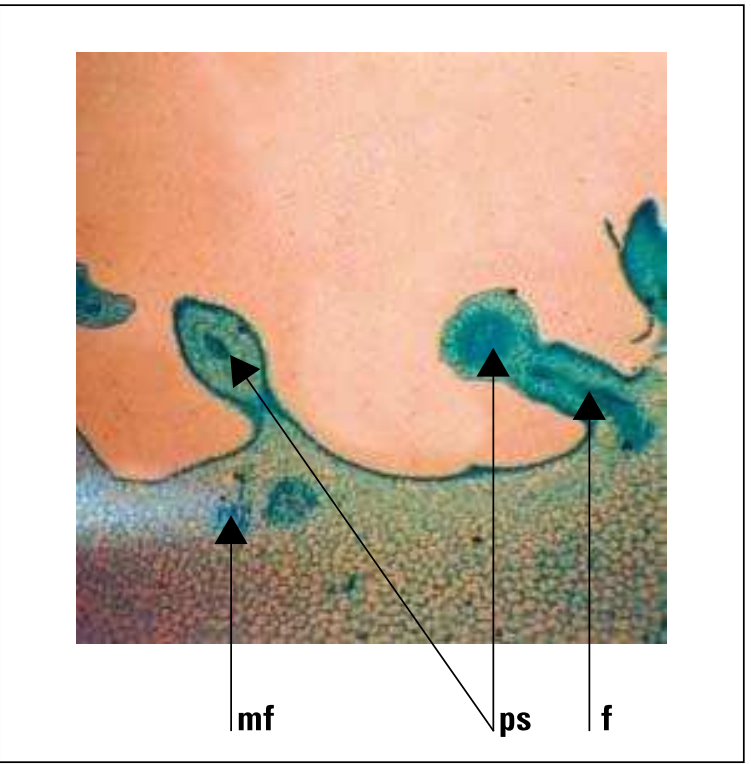

Figura 2. Panorámica de los primordios seminales (ps) en papaya. Funículo (f), mesocarpo del fruto (mf). Aumento de 4X.

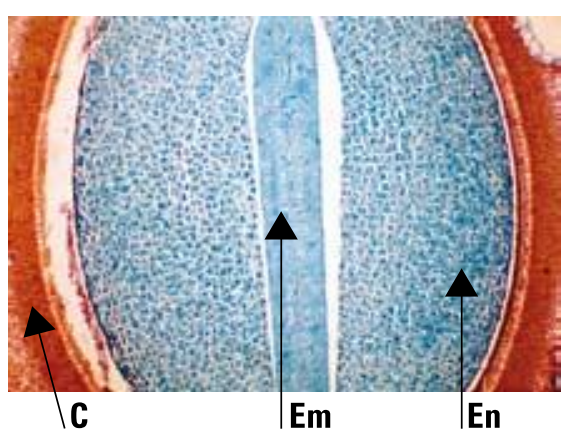

Figura 4. Vista parcial de semilla de papaya de 120 días. Cubierta seminal (C), endospermo (En), embrión (Em). Aumento de 10X.

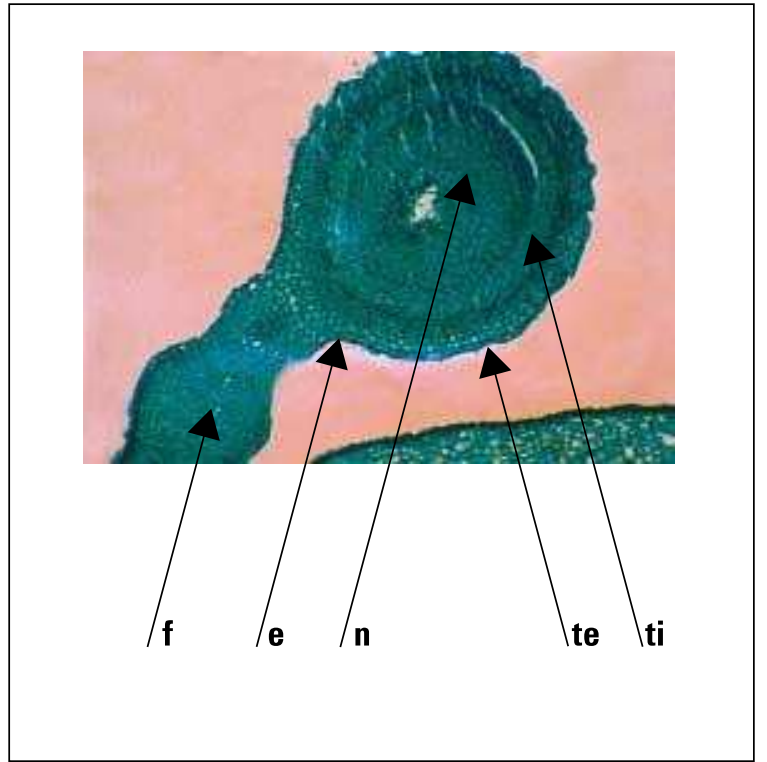

Figura 3. Primordio seminal con capas celulares concéntricas correspondientes a los tegumentos. Epidermis (e) funículo (f), nucela (n), tegumento externo (te), tegumento interno (ti). Aumento de 10X.

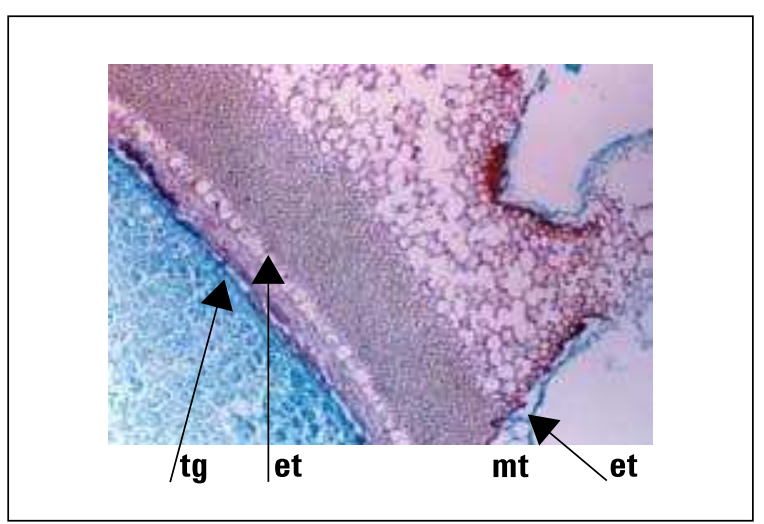

Figura 5. Componentes de la cubierta seminal de la semilla de papaya. Exotesta (ex), mesotesta (mt) endotesta (et) y tegmen (tg). Aumento de 10X. 
Las raíces laterales se originan a partir de un pequeño número de células diferenciadas situadas en la periferia de los tejidos vasculares. En Arabidopsis, las raíces laterales son derivadas a partir de las células del periciclo adyacentes a los polos xilemáticos, llamadas células fundadoras del periciclo (Casimiro et al., 2001). Dichas células experimentan un programa definido de divisiones y expansiones para formar un primordio lateral radicular. El primer paso en el desarrollo lateral de raíces ocurre en las tres filas de células adyacentes al periciclo. Una división anticlinal polarizada tiene lugar en dos células fundadoras por fila conllevando a la formación de dos pequeñas células hijas encerradas por dos células más grandes (estado I). Divisiones anticlinales, expansión celular y divisiones periclinales dan lugar a un primordio lateral radicular de cuatro capas (estado IV). Más divisiones y expansión resultan en la formación de un estado complejo (estado VI) cuya organización es similar al meristemo de la raíz primaria. La expansión celular conlleva a la emergencia de primordios laterales radiculares a partir de la raíz primaria (estado VIII) (Laplaze et al., 2007).

\section{CONCLUSIONES}

La semilla de papaya está constituida por tres partes principales: la cubierta seminal, el endospermo y el embrión.

Por ser bitegumentada, la cubierta seminal de la semilla de papaya posee testa y tegmen. La testa se compone de la sarcotesta o exotesta jugosa, la cual recubre la mesotesta, compuesta a su vez por la mesotesta externa e interna, y la endotesta, que corresponde a la parte más interna. El tegmen está compuesto por tres partes denominadas exotegmen, mesotegmen y endotegmen, en estrecho contacto con el endospermo de la semilla.

El endospermo de la semilla de papaya está constituido principalmente por lípidos y proteínas, almacenados en estructuras denominadas granos de aleurona.

En el embrión se encontró que los cotiledones están compuestos por la epidermis adaxial y abaxial, además de cuatro capas celulares internas ordenadas, y en la zona radicular se observó el esbozo de raíces secundarias laterales.

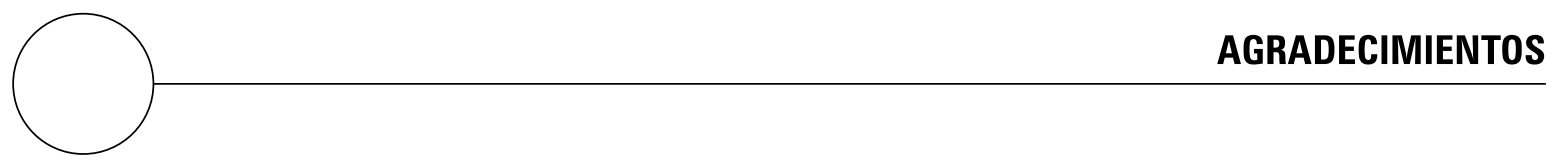

A William López, laboratorista de la sección de Histotecnia, Departamento de Biología, Universidad Nacional de Colombia, por su colaboración para la realización de los cortes en micrótomo y el teñido del material vegetal presentado en este artículo.

A la profesora Martha de Valencia, Departamento de Biología, Universidad Nacional de Colombia, por su ayuda en la identificación de algunas estructuras anatómicas del material vegetal. 


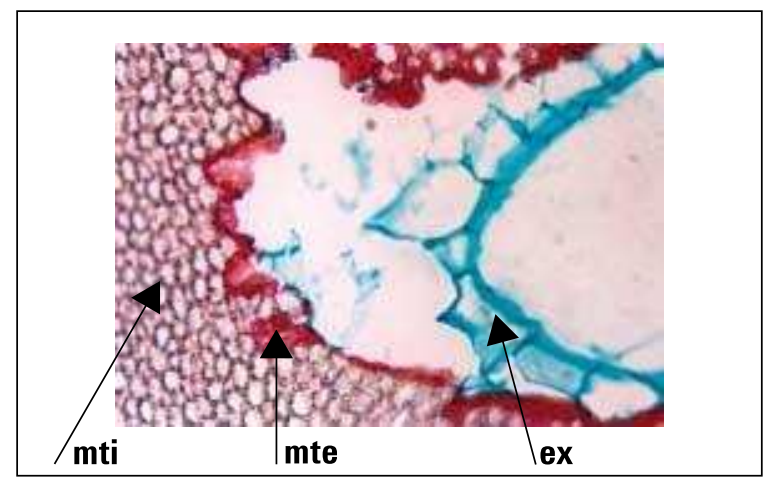

Figura 6. Detalle de la exotesta (ex), mesotesta externa (mte) y mesotesta interna (mti) en la semilla de papaya. Aumento de 45X.

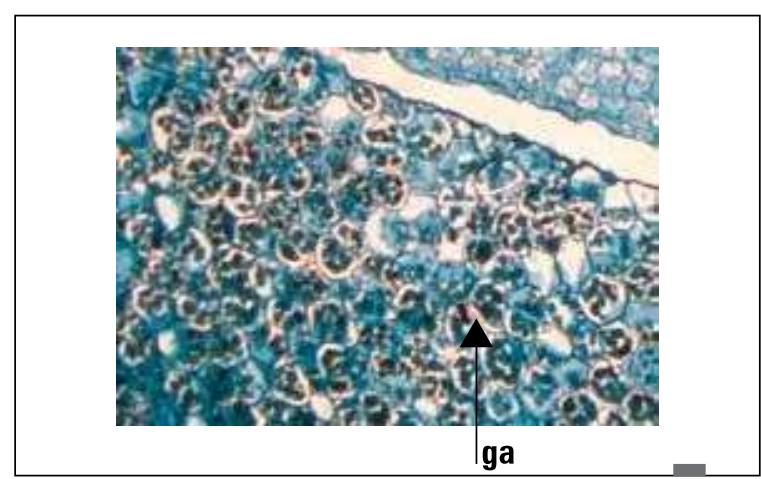

Figura 8. Granos de aleurona (ga) en el endospermo de semilla de papaya. Aumento de 45X.

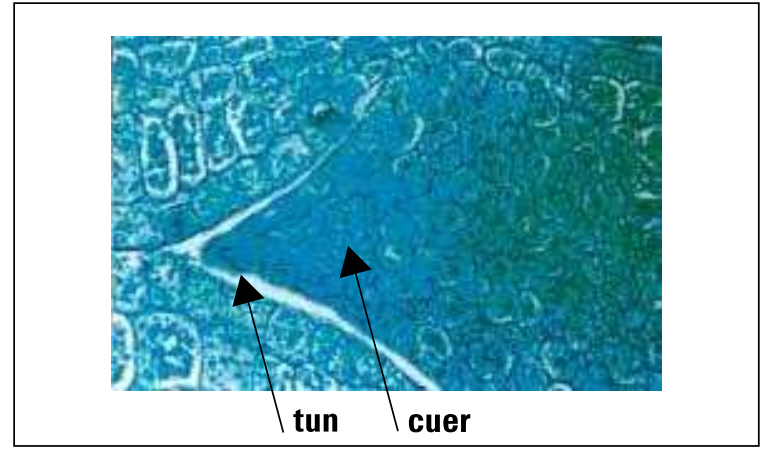

Figura 10. Detalle del ápice del embrión mostrando la túnica (tun) y el cuerpo (cuer). Aumento de 45X.

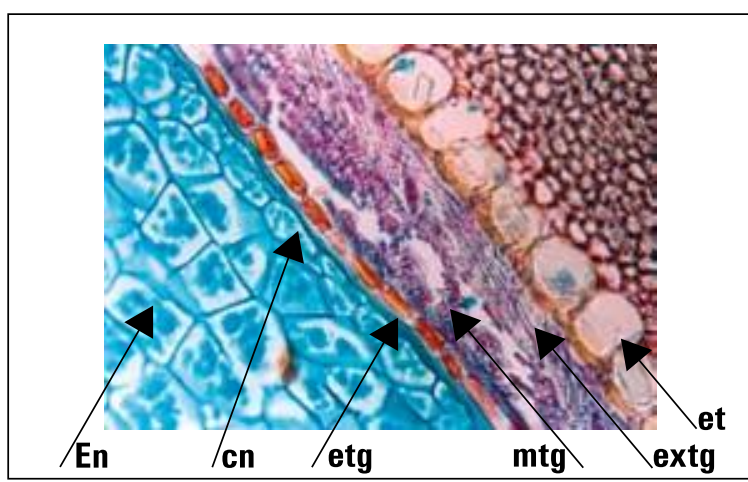

Figura 7. Endotesta (et), exotegmen (extg), mesotegmen (mtg), endotegmen (etg) y cutícula nucelar (cn) en la semilla de papaya. Endospermo (En). Aumento de 45X.

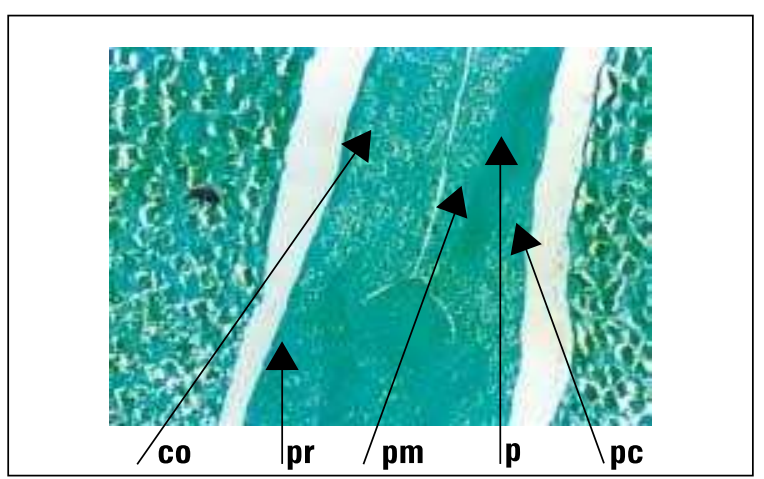

Figura 9. Vista parcial del embrión de la semilla de papaya. Protodermis (pr), parénquima cortical (pc), parénquima medular (pm), procambium (p), cotiledón (co). Aumento de 10X.

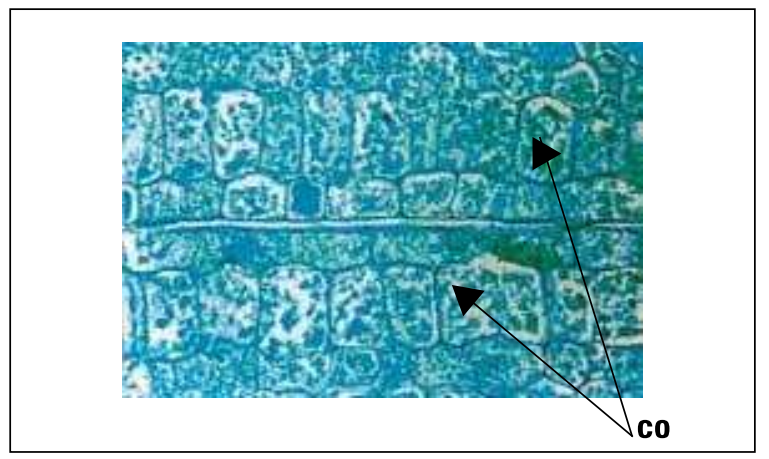

Figura 11. Vista parcial de las capas celulares de los cotiledones (co). Aumento de 45X.

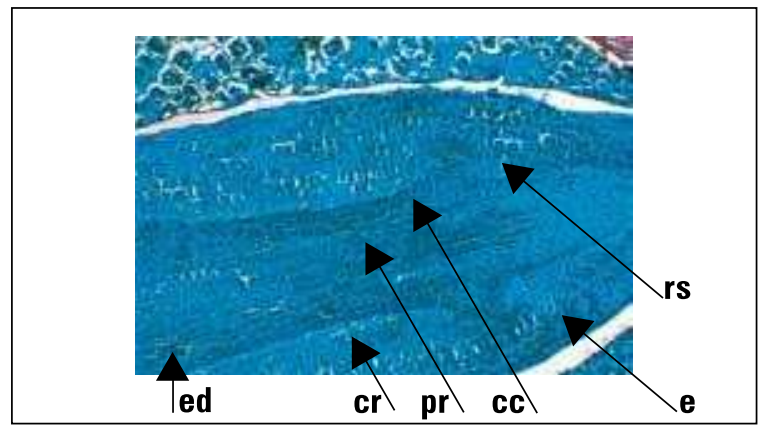

Figura 12. Esbozo de raíces secundarias (rs). Endodermis (ed), córtex (cr). periciclo (pr), cilindro central (cc), epidermis (e). Aumento de 10X. 


\section{REFERENCIAS BIBLIOGRÁFICAS}

Andre, C.; J.R. Froehlich; M.R. Moll y C. Benning. 2007. A heteromeric plastidic pyruvate kinase complex involved in seed oil biosynthesis in Arabidopsis. Plant Cell 19, 2006-2022.

Anil, V.S.; A.C. Harmon y K.S. Rao. 2003. Temporal association of $\mathrm{Ca}^{2+}$-dependent protein kinase with oilbodies during seed development in Santalum album L.: Its biochemical characterization and significance. Plant Cell Physiol.44, 367-376.

Baroux, C.; A. Pecinka; J. Fuchs; I. Schubert y S. Grossniklau. 2007. The triploid endosperm genome of Arabidopsis adopts a peculiar, parental-dosage-dependent chromatin organization. Plant Cell 19, 1782-1794.

Barton, M.K. y R.S. Poethig. 1993. Formation of the shoot apical meristem in Arabidopsis thaliana: an analysis of development in the wild type and in the shoot meristemless mutant. Development 119, 823-831.

Becerra, N. y M. Chaparro. 1999. Morfología y anatomía vegetal. Departamento de Biología, Facultad de Ciencias, Universidad Nacional de Colombia, Bogotá.

Beeckman, T.; R. de Rycke; R. Viane y R. Inze. 2000. Histological study of seed coat development in Arabidopsis thaliana. J. Plant Res. 113, 139-148.

Besnier, F. 1988. Semillas: biología y tecnología. Ediciones Mundi-Prensa, Madrid.

Casimiro, I.; A. Marchant; R. Bhalerao; T. Beeckman; S. Dhoge; R. Swarup; N. Graham; D. Inze; G. Sandberg; P. Casero y M. Bennet. 2001. Auxin transport promotes Arabidopsis lateral root initiation. Plant Cell 13, 843-852.

Chandler, J.W. 2008. Cotyledon organogénesis. J. Exp. Bot. 59(11), 2917-2931.

Chaudhury, A.M. y F. Berger. 2001. Maternal control of seed development. Cell Dev. Biol. 12, 381-386.

Debeaujon, I.; K.M. León-Kloosterziel y M. Koornneef. 2000. Influence of the testa on seed dormancy, germination, and longevity in Arabidopsis. Plant Physiol. 122, 403-413.

Esau, K. 1985. Anatomía vegetal. Ediciones Omega, Barcelona, España. pp. 641-659.

Fahn, A. 1985. Anatomía vegetal. Ediciones Pirámide, Madrid. pp. 528-554.
Font Quer, P. 1965. Diccionario de botánica. Editorial Labor, Barcelona, España.

Fosket, D.E. 1994. Plant growth and development: a molecular approach. Academic Press, San Diego, CA.

Garcia. D.; J. Fitzgerald y F. Berger. 2005. Maternal control of integument cell elongation and zygotic control of endosperm growth are coordinated to determine seed size in Arabidopsis. Plant Cell 17, 52-60.

García, D.; V, Saingery; P, Chambrier; U, Mayer; G, Jürgens y F. Berger. 2003. Arabidopsis haiku mutants reveal new controls of seed size by endosperm. Plant Physiol. 131, 1661-1670.

Haig, D. y M. Westoby. 1989. Parent-specific gene expression and the triploid endosperm. Amer. Nat. 134, 147-155.

Imlau, A.; E. Truernit y N. Sauer. 1999. Cell-to-cell and long-distance trafficking of the green fluorescent protein in the phloem and symplastic unloading of the protein into sink tissues. Plant Cell 11, 309-322.

Ingouff, M; P.E. Jullien y F. Berger. 2006. The female gametophyte and the endosperm control cell proliferation and differentiation of the seed coat in Arabidopsis. Plant Cell 18, 3491-3501.

Johansen, D.A. 1940. Plant microtechnique. Mc GrawHill Book Company, New York, NY.

Laplaze, L.; E. Benkova; I. Casimiro; L. Maes; S. Vanneste; R. Swarup; D. Weijers; V. Calvo; B. Parizot M.B. Herrera-Rodríguez; R. Offringa; N. Graham, P. Doumas; J. Friml; D. Bogusz; T. Beeckman y M. Bennet. 2007. Cytokinins act directly on lateral root founder cells to inhibit root initiation. Plant Cell 19, 3889-3900.

Laux, T.; T. Würschum y H. Breuninger. 2004. Genetic regulation of embryonic pattern formation. Plant Cell 16, S190-S202.

León, J. 1987. Botánica de los cultivos tropicales. Segunda edición. Instituto Interamericano de Cooperación para la Agricultura (IICA), San José. pp. 375 379.

Léon-Kloosterziel, K.M.; C.J. Keijzer y M. Koornneef. 1994. A seed shape mutant of Arabidopsis that is affected in integument development. Plant Cell 6, 385-392

Lopes, M.A. y B.A. Larkins. 1993. Endosperm origin, development and function. Plant Cell 5, 1383-1399. 
Nakaune, S.; K. Yamada; M. Nondo; T. Kato; T. Satoshi; M. Nishimura y I. Hara-Nishimura. 2005. A vacuolar processing enzyme, VPE, is involved in seed coat formation at the early stage of seed development. Plant Cell 17, 876-887.

Niembro, A. 1988. Semillas de árboles y arbustos: ontogenia y estructura. Limusa, México.

Penfield, S.; Y. Li; A. Gilday; S. Graham e I. Graham. 2006. Arabidopsis ABA INSENSITIVE4 regulates lipid mobilization in the embryo and reveals repression of seed germination by the endosperm. Plant Cell 18, 1887-1899.

Reiser, L. y R. Fischer. 1993. The ovule and the embryo sac. Plant Cell 5, 1291-1301.

Ren, C. y J.D. Bewley. 1998. Seed development, testa structure and precocious germination of Chinese cabbage (Brassica rapa subsp. pekinensis). Seed Sci. Res. 8, 385-397.

Schruff, M.; M. Spielman; S. Tiwari; S. Adams; N. Fenby y R. Scott. 2006. The AUXIN RESPONSE FACTOR 2 gene of Arabidopsis links auxin signalling, cell division, and the size of seeds and other organs. Development 133, 251-261.

Siegfried, K.R.; Y. Ehed; S.F. Baum; D. Otsuga; G. Drews y J. Bowman. 1999. Members of the YABBY gene family specify abaxial cell fate in Arabidopsis. Development 126, 4117-4128.
Siloto, R.; K. Findlay; A. Lopez-Villalobos; E. Yeung; C. Nykiforuk y M. Moloney. 2006. The accumulation of oleosins determines the size of seed oilbodies in Arabidopsis. Plant Cell 18, 1961-1974.

Skinner, D.; T. Hill y C. Gasser. 2004. Regulation of Ovule Development. Plant Cell 16, S32-S45.

Stadler, R.; C. Lauterbach y N. Sauer. 2005. Cell-to-cell movement of green fluorescent protein reveals post-phloem transport in the outer integument and identifies symplastic domains in Arabidopsis seeds and embryos. Plant Physiol. 139, 701-712.

Szymkowiak, E.J. e I.M. Sussex. 1996. What chimeras can tell us about plant development. Annu. Rev. Plant Physiol. Plant Mol. Biol. 47, 351-376.

Webb, M. y B. Gunning. 1990. Embryo sac development in Arabidopsis thaliana. 1. Megasporogenesis, including the microtubular cytoskeleton. Sex. Plant Reprod. 3, 244-256.

Western, T.L.; D.J. Skinner y G.W. Haughn. 2000. Differentiation of mucilage secretory cells of the Arabidopsis seed coat. Plant Physiol. 122, 345-355.

Windsor, J.B.; V. Symonds; J. Mendenhall y A.M. Lloyd. 2000. Arabidopsis seed coat development: Morphological differentiation of the outer integument. Plant J. 22, 483-493. 